Acta Technologica Agriculturae 4

Nitra, Slovaca Universitas Agriculturae Nitriae, 2016, pp. 107-109

\title{
PRODUCTION METHOD THAT LEADS TO TIO 2 NANOFIBROUS STRUCTURE USABLE IN FOOD PACKAGING
}

\author{
Radovan KOVÁŘ \\ Technical University of Liberec, Czech Republic
}

\begin{abstract}
Burned inorganic nanofibers most often occur in the nature in two forms: rutile and anatase. Today, the production of rutile is about to end, while anatase provides more application possibilities. The resulting fiber structure is determined by calcination. It is necessary to find the optimal temperature as well as time, during which the fibers must withstand temperature load. For such method of calcination, it is necessary to create a special design of continuous furnace. Anatase has application in food packaging. Packages containing anatase are used for: food safety, improved packaging for spoilage reduction, sensors for detection of pathogens and spoilage, disinfectants and antimicrobial surfaces.
\end{abstract}

Keywords: nanofibers; calcination; anatase; photocatalysis; self-cleaning

While rutile (titanium dioxide pigment) has been produced commercially for many years, production of materials based on anatase have only recently come to the forefront because of the extraordinary properties of this crystalline form. Anatase has many interesting features, the most wellknown being its photocatalytic activity and photocatalytic induced superhydrophilicity. Photocatalytic activity leads to the degradation of organic structures (organic pollutants and microorganisms) on the surface of $\mathrm{TiO}_{2}$ by radiation with a wavelength below $390 \mathrm{~nm}$. This effect means that $\mathrm{TiO}_{2}$ based materials can be applied to disinfection use, for self-cleaning and antibacterial layers (He et al., 2014). $\mathrm{TiO}_{2}$ nanofibers in combinations with clay can be used for active packaging films. Packaging film offers combination of low permeability to oxygen and carbon dioxide (clay). Second property is antimicrobial activity when exposed to UV-light (titanium dioxide). In the industry, the nanoparticles $\mathrm{TiO}_{2}$ are frequently used in food packaging. Usage of nanofibers reduces the risk of transfer of harmful elements into the human body. Moreover, the nanofibers are more easily degradable in the human organism.

\section{Material and methods}

\section{Calcination analysis}

Calcination was optimized on the basis of the effect of increase in temperature, maximum temperature, duration at the maximum temperature, and composition of the atmosphere (air, oxygen) on the resulting $\mathrm{TiO}_{2}$ phase composition.

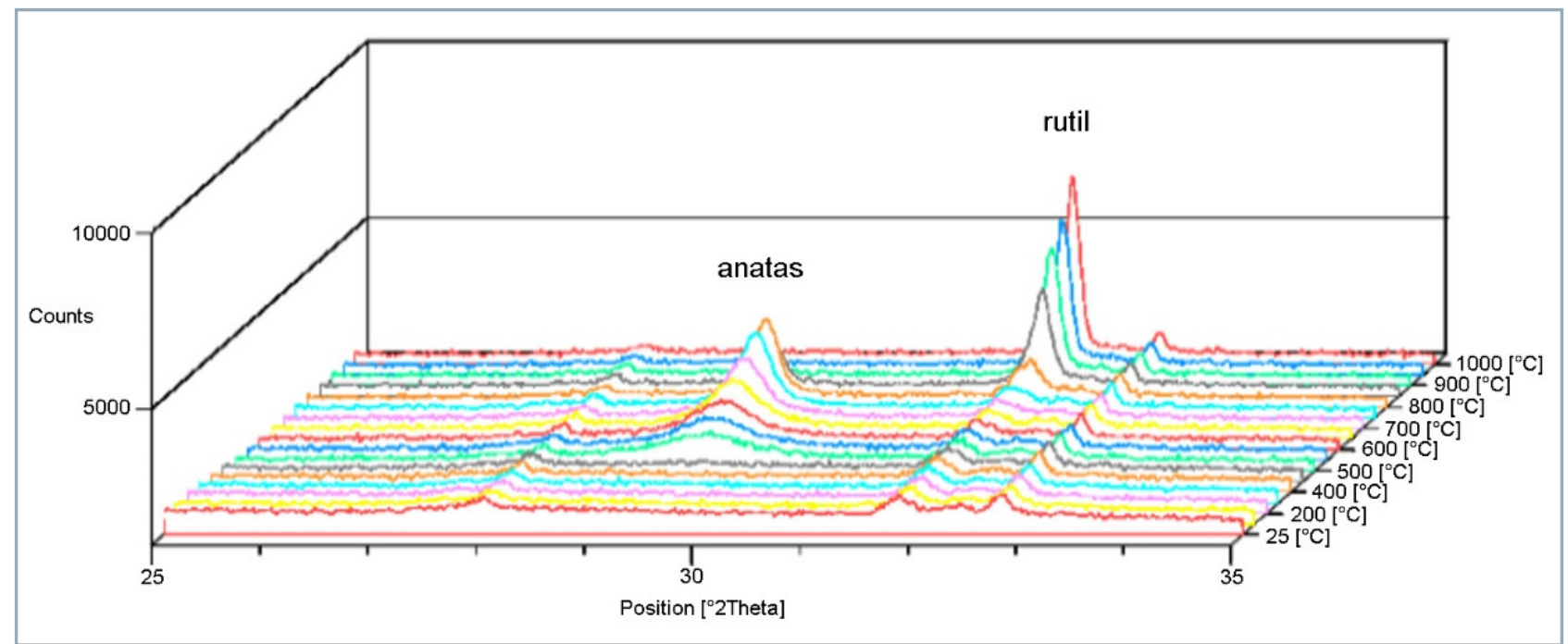

Figure 1 High-temperature X-ray analysis of $\mathrm{TiO}_{2}$ precursor 


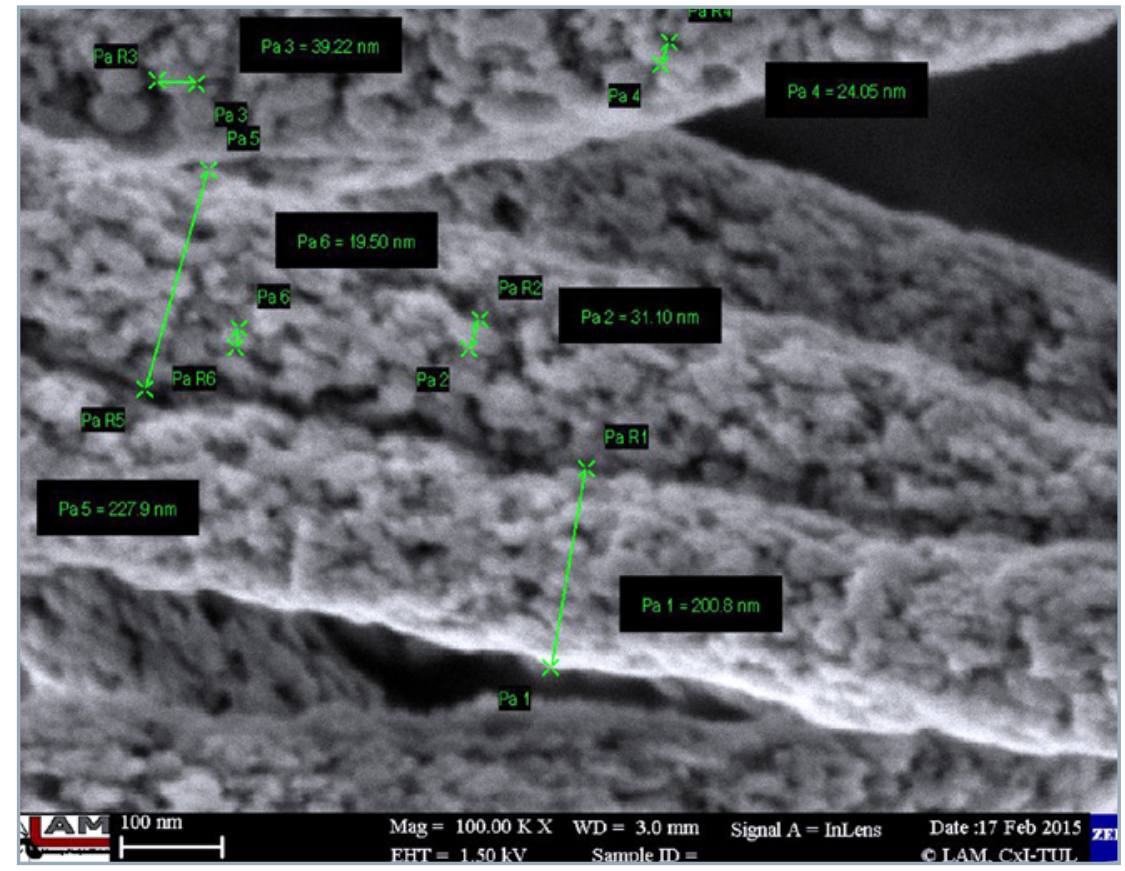

Figure 2 High-tech Electron microscope image of the resulting nanofibrous structure of $\mathrm{TiO}_{2}$

High-temperature X-ray was used for a rough estimation of the maximum temperature. The phase composition of the calcined samples and the amount of residual carbon were examined using X-ray powder diffraction and the EDX method (Energy-dispersive analysis of X-rays), respectively. Based on the results of the high-temperature X-ray analysis, a maximum temperature of $600{ }^{\circ} \mathrm{C}$ was determined. This determination is shown in Figure 1.

\section{Experiment}

Annealing in oxygen presence leads to rapid oxidation, burning of the sample and the formation of a rutile phase. Calcination proceeds in two steps. In the first step, the sample is heated to the temperature of $600^{\circ} \mathrm{C}$; the temperature rising speed was observed to be $1{ }^{\circ} \mathrm{C}$ per min. In the second step, the sample is continuously heated for 120 minutes at the temperature of $600{ }^{\circ} \mathrm{C}$. After calcination process, the sample was milled in a bead mill with agate balls in order to disperse clusters of fibres and to analyse composition phase, specific surface area by BET (Brunauer-EmmettTeller) and to measure photoactivity. After the fibres dispersion in the mill, the nanofibrous morphology of the sample was examined using SEM (Scanning electron microscope), as it is shown in Figure 2. It was found that the nanofibrous morphology was retained, but the fibres were shorter due to the milling. It was determined that the sample contained a pure anatase phase of $\mathrm{TiO}_{2}$ and the size of primary crystallites was between $19 \mathrm{~nm}$ and $35 \mathrm{~nm}$.

\section{Design of calcination device}

Calcining system is a precursor of finished product. During calcination oxidation of the excess material, the pure nanofibers in crystalline form are subsequently obtained. On calcining system, as part of the production line, there are high demands in terms of continuous production, accurate control of the temperature zones. Using the appropriate temperature control, it is possible to achieve the desired structure of the resulting material. These conditions can be solved with continuous furnaces with a metallic endless belt passing through several temperature zones which are regulated by oxygen supply. Before entering the ovens, the precursor is sprinkled onto the belt which transports it through a calcining furnace chamber. The burned material falls down from the outlet of the furnace into the prepared transport box.

Using many simulations, the resulting study can approximate the distribution of temperature and flow vectors of designed parts in furnace geometry, which could significantly

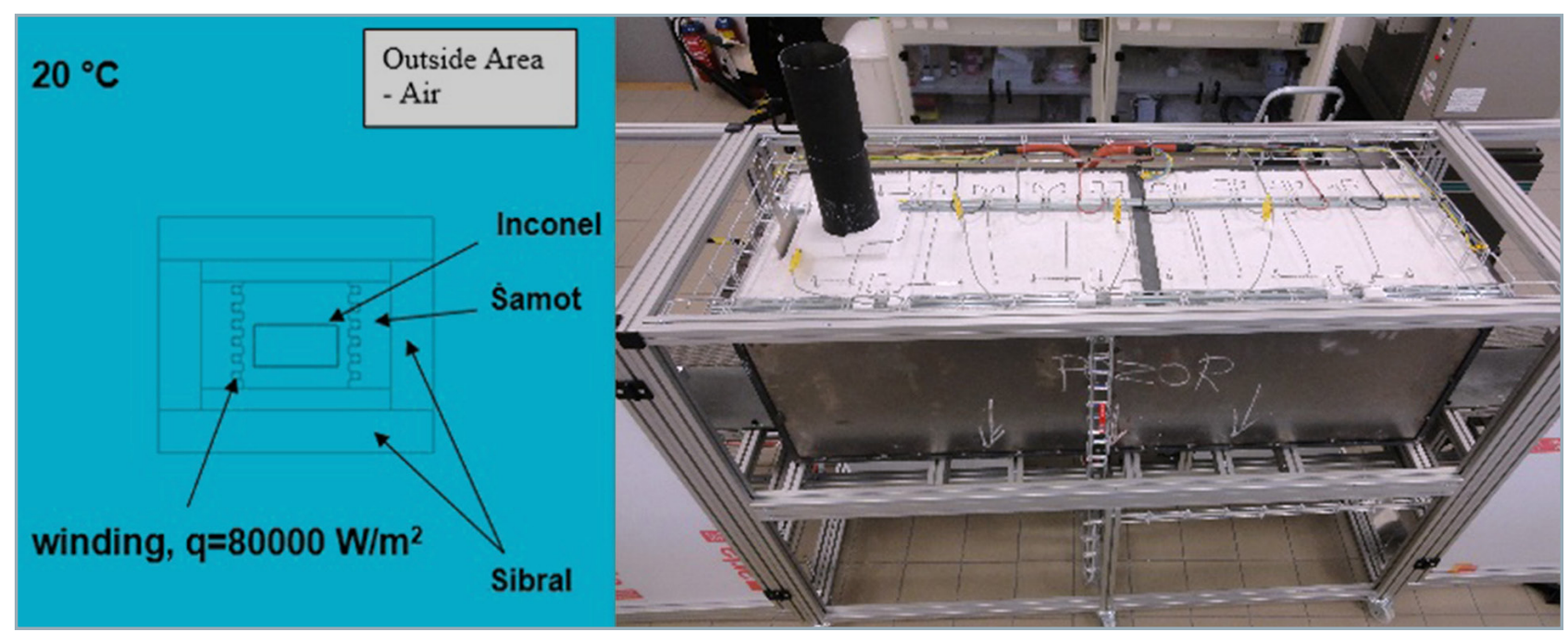

Figure 3

Design of calcination furnace with cross section to show the internal structure 
contribute to optimizing of the design temperature profiles and sites with vapour recovery. Temperature field which spreads through the furnace structure may be characterized as distributed stationary area $(t=0)$ with a downward trend in temperature; the maximum temperature is near the heat source (spiral wound) and the minimum temperature is compared with the temperature of the external environment. Stationary three-dimensional temperature field is then given by the scalar function (1):

$$
T=f(x, y, z)
$$

where:

$\mathrm{T}$ - temperature

$x, y, z-$ axes of the basic coordinate system

Stationary heat conduction can be subsequently described using Fourier law of heat conduction according to Equation (2):

$$
-\lambda \cdot \nabla T=q
$$

where:

$$
\begin{array}{ll}
\lambda & - \text { the thermal conductivity coefficient }\left(\mathrm{W} \mathrm{m}^{-1} \mathrm{~K}^{-1}\right) \\
\nabla T & - \text { temperature gradient } \\
q & - \text { density of heat flow }\left(\mathrm{W} \mathrm{m}^{-2}\right)
\end{array}
$$

There is shown the design of heating furnace with cross-section. For construction, it is appropriate to use material with high temperature resistance as Inconel sheet for calcination chamber creation. The heating winding fire clay blocks were used for placing and Sibral is also a good isolation (Ševčík et al., 2014).

\section{Conclusion}

The method, which leads to the determination of optimal temperature as well as of the optimal time was described in the paper. During the experiment, a temperature of $600{ }^{\circ} \mathrm{C}$ was observed as maximal appropriate temperature. At the temperatures below this value, a crystalline phase of anatase was formed. At temperatures above this value, anatase structure transforms into the rutile structure. Different transition temperature values were observed by Wetchakun (Wetchakun et al., 2012). A sol-gel method for the production of nanofibrous structure was used in her work. It indicated that anatase is transformed to rutile within the range of temperatures between $500-600{ }^{\circ} \mathrm{C}$. When the temperature reached $600{ }^{\circ} \mathrm{C}$, there was observed just rutile. It follows that the fibers produced by electrostatic spinning method have a higher resistance to high temperatures, because the transition phase takes place later during heating. In order to attain such conditions during the burning process, it was introduced to the design and construction of the calcination furnace. The product of this device is nanofibers $\mathrm{TiO}_{2}$ in a specific form. Such product is useful in food packaging, where it contributes to the elimination of bacteria, fungi and microorganisms using photocatalytic process.

\section{Acknowledgement}

This work was supported by the Ministry of Education of the Czech Republic within the SGS project no. 21007 at the Technical University of Liberec.

\section{References}

HE, F. - MA, F. - LI, J. - LI. T. - LI. G. 2014. Effect of calcination temperature on the structural properties and photocatalytic activities of solvothermal synthesized $\mathrm{TiO}_{2}$ hollow nanoparticles. In Ceramics International, vol. 40, 2014, no. 5, pp. 6441-6446.

ŠEVČÍK, L. - LEPŠÍK, P. - PETRŮ, M. - MAŠÍN, I. - MARTONKA, R. 2014. Modern method of construction design. In Book of Proceedings of $54^{\text {th }}$ International Conference of Machine Departments. Liberec : Technical University of Liberec, 2014. pp. 509-516. ISBN 978-3-319-05203-8.

WETCHAKUN, N. - INCESSUNGVORN, B. - WETCHAKUN, K. 2012. Influence of calcination temperature on anatase to rutile phase transformation in $\mathrm{TiO}_{2}$ nanoparticles synthesized by the modified sol-gel method. In Materials Letters, vol. 82, 2012, September, pp. 195-198. 